Article

\title{
Species Composition and Toxigenic Potential of Fusarium Isolates Causing Fruit Rot of Sweet Pepper in China
}

\author{
Jianhua Wang ${ }^{1}$, Shuangxia Wang ${ }^{2}$, Zhiyong Zhao ${ }^{1}$, Shanhai Lin ${ }^{1,3}$, François Van Hove ${ }^{4}$ and \\ Aibo $\mathrm{Wu}^{2, * \text { (D) }}$ \\ 1 Institute for Agri-food Standards and Testing Technology, Shanghai Academy of Agricultural Sciences, \\ 1000 Jinqi Road, Shanghai 201403, China; wangjianhua@saas.sh.cn (J.W.); zhaozhiyong@saas.sh.cn (Z.Z.); \\ linshanhai@gxaas.net (S.L.) \\ 2 SIBS-UGENT-SJTU Joint Laboratory of Mycotoxin Research, CAS Key Laboratory of Nutrition, Metabolism \\ and Food Safety, Shanghai Institute of Nutrition and Health, Shanghai Institutes for Biological Sciences, \\ Chinese Academy of Sciences, University of Chinese Academy of Sciences, Shanghai 200000, China; \\ shuangxiawang@163.com \\ 3 Sugarcane Research Institute, Guangxi Academy of Agricultural Sciences, Nanning 530007, China \\ 4 Mycothèque de l'UCL catholique de Louvain (BCCMTM/MUCL), Applied Microbiology (ELIM), \\ Earth and Life Institute (ELI), Université catholique de Louvain (UCL), B-1348 Louvain-la-Neuve, Belgium; \\ francois.vanhove@uclouvain.be \\ * Correspondence: abwu@sibs.ac.cn; Tel.: +86-21-5492-0926
}

Received: 28 October 2019; Accepted: 21 November 2019; Published: 24 November 2019

\begin{abstract}
Apart from causing serious yield losses, various kinds of mycotoxins may be accumulated in plant tissues infected by Fusarium strains. Fusarium mycotoxin contamination is one of the most important concerns in the food safety field nowadays. However, limited information on the causal agents, etiology, and mycotoxin production of this disease is available on pepper in China. This research was conducted to identify the Fusarium species causing pepper fruit rot and analyze their toxigenic potential in China. Forty-two Fusarium strains obtained from diseased pepper from six provinces were identified as F. equiseti (27 strains), F. solani (10 strains), F. fujikuroi (five strains). This is the first report of F. equiseti, F. solani and F. fujikuroi associated with pepper fruit rot in China, which revealed that the population structure of Fusarium species in this study was quite different from those surveyed in other countries, such as Canada and Belgium. The mycotoxin production capabilities were assessed using a well-established liquid chromatography mass spectrometry method. Out of the thirty-six target mycotoxins, fumonisins $\mathrm{B}_{1}$ and $\mathrm{B}_{2}$, fusaric acid, beauvericin, moniliformin, and nivalenol were detected in pepper tissues. Furthermore, some mycotoxins were found in non-colonized parts of sweet pepper fruit, implying migration from colonized to non-colonized parts of pepper tissues, which implied the risk of mycotoxin contamination in non-infected parts of food products.
\end{abstract}

Keywords: Fusarium species; mycotoxin; toxigenic profile; mycotoxin migration; sweet pepper; fungal disease

Key Contribution: Fusarium species on sweet pepper in China is different from those in Canada and Belgium, and F. equiseti, F. solani, and F. fujikuroi were first reported causing pepper fruit rot in China. Toxigenic potential of Fusairum strains were analyzed in inoculated pepper fruit and diffusions of FA (fusaric acid), $\mathrm{FB}_{1}$ (fumonisin $\mathrm{B}_{1}$ ), $\mathrm{FB}_{2}$ (fumonisin $\mathrm{B}_{2}$ ), and $\mathrm{MON}$ (moniliformin) from lesions into the surrounding sound tissues were observed. This is the first report about the migration of FA and $\mathrm{MON}$ in sweet peppers. 


\section{Introduction}

Sweet pepper or bell pepper (Capsicum annuum L.) is highly appreciated in the fresh vegetable markets worldwide due to its unique taste, aromas, and the multiple culinary uses. It represents one of the most important vegetables for the high content of phytochemicals, such as ascorbic acid and soluble phenols [1,2], having potential positive effects on human health. For example, ascorbic acid is an essential dietary nutrient in the human body with its vital biological function as an antioxidant. Sweet pepper is an economically important vegetable crop and widely used for direct consumption and manufacturing of sauce worldwide, where the global production reached 34.6 million tons of fresh fruit and 3.5 million tons of dried pods [3]. China is the largest producer and exporter of sweet pepper in the world, with a total fresh pepper production per year of almost 23 million tons. Sweet pepper is often grown in commercial greenhouses, which is favorable for the growth and survival of phytopathogenic fungi and the infection of pepper plants [4]. Thus, the disease poses a serious limitation to pepper cultivation, resulting in yield reduction or complete crop loss, as reported previously in the literature [4-6].

Several fungal diseases have caused economic losses in sweet pepper production in Canada, United Kingdom, and Belgium $[4,7,8]$. Fusarium infection on the stem- and blossom-end of pepper fruit caused by $F$. solani was first reported in Ontario and British Columbia in 1991 and caused approximately 5\% fruit-yield loss [8-10]. Since the 1990s, this rot disease has been an increasing problem in pepper production in both Europe and North America [7,11,12]. More seriously, a severe outbreak of this disease resulting in a 50\% yield loss in a greenhouse was reported in 1990 in Ontario [13].

In addition to external fruit rot, internal rot of sweet pepper fruit is also a big problem in pepper production [14]. In contrast to the external pepper fruit rot, the fruit is infected internally by a fungus. Unless severely infected and rotten, most infected fruits are difficult to cull before delivery to the market as the symptoms are not readily visible $[4,8,10]$. A comprehensive histopathology analysis performed by Yang et al. [10] indicated that internal fruit rot of greenhouse sweet pepper caused by F. lactis was initiated through the infection of the stigma and style during anthesis. Symptomless seed infection may contribute to disease spread, and air and insects also play an important role as intermediates in fungal spores spreading [15]. Based on the surveys to date, F. lactis is the principal causal agent of internal fruit rot of pepper, although the closely related Fusarium species belonging to the Fusarium fujikuroi species complex (FFSC), such as F. proliferatum, F. subglutinans, and F. verticillioides, have also been implicated in this disease $[4,6,8]$.

Apart from causing significant yield losses, Fusarium species can produce fumonisins (FBs), trichothecenes (TCs), zearalenone (ZEN), and other mycotoxins in infected plant tissues which are harmful to consumers. For example, B-series fumonisins (Figure 1), which are mainly produced by Fusarium species from FFSC, are the most frequently detected mycotoxins in maize, and are involved in animal and human diseases by interfering with sphingolipid metabolism. Moreover, fumonisins have been associated epidemiologically with esophageal cancer in humans in some regions of the world [16,17]. On the basis of available toxicological evidence, the International Agency for Research on Cancer (IARC) has classified fumonisins as possibly carcinogenic (Group 2B) [18]. Mycotoxin contamination in grains, vegetables, and fruit poses a serious threat to food safety.

Mycotoxins can diffuse into tissues surrounding the pathogen-infected site. The water content of fresh sweet pepper is usually higher than $90 \%$, which contributes to the dissolution of polar compounds produced by pathogens in pepper tissues. Fumonisins, fusaric acid (FA), and moniliformin (MON) are the most common mycotoxin contaminants produced by Fusarium species, and migration of some of these toxins has been reported in pepper and fruit previously $[19,20]$. A migration study of beauvericin (BEA) and fumonisins was reported by Monbaliu et al. [19], and the results indicated the migration of fumonisins into healthy parts of the sweet pepper, while beauvericin was not detected in the tissue surrounding the lesion. Mycotoxin contaminations originating from mycotoxin-producing Fusarium species in pepper should be considered as an importantly sensitive food safety concern. Therefore, it is 
of great necessity to assess the types and levels of mycotoxin contamination in pepper and its derived products [4].

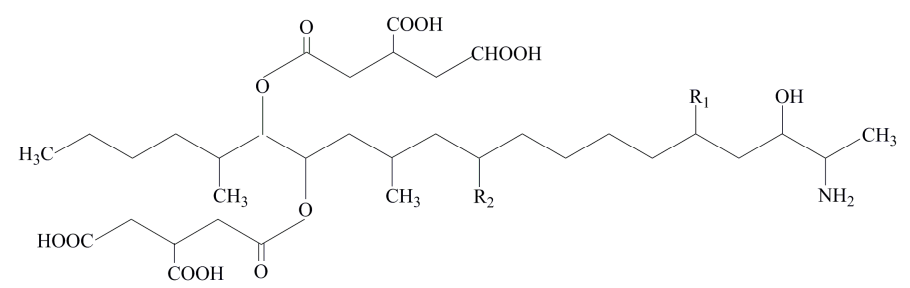

\begin{tabular}{ccc}
\hline Figure & $\mathbf{R}_{\mathbf{1}}$ & $\mathbf{R}_{\mathbf{2}}$ \\
\hline Fumonisin $\mathrm{B}_{1}$ & $\mathrm{OH}$ & $\mathrm{OH}$ \\
Fumonisin $\mathrm{B}_{2}$ & $\mathrm{OH}$ & $\mathrm{H}$ \\
Fumonisin $\mathrm{B}_{3}$ & $\mathrm{H}$ & $\mathrm{OH}$ \\
\hline
\end{tabular}

Figure 1. Structural formulas of B-series fumonisins.

Effective management of mycotoxin contamination in sweet pepper relies on the control of the fungal infection and requires a better understanding of Fusarium biology and epidemiology. To our best knowledge, there is little information on the causal agent, etiology, toxigenic potential, and geographic distribution of the Fusarium species involved in pepper disease in China. The objectives of this current work were: (i) To isolate and identify the causal organism from Fusarium genus on sweet pepper in China; (ii) to assess the potential mycotoxin profiling of the fungal pathogens; (iii) to estimate the migration behavior of mycotoxins in sweet pepper.

\section{Results and Discussion}

\subsection{Isolation and Identification of Fusarium Isolates}

Sweet pepper fruits were sampled from Hainan, Heilongjiang, Hunan, Shanghai, Shandong, and Zhejiang provinces in China. Following isolation from diseased pepper tissues, a total of forty-two single-spore isolates were obtained and identified as belonging to Fusarium genus by morphology. Two of theses strains were isolated from Hainan, one strain was isolated from Heilongjiang, five strains were isolated from Hunan, twenty-one strains were isolated from Shanghai, three strains were isolated from Shandong, and ten strains were isolated from Zhejiang (Table 1).

The purified isolates were first identified to species with morphological characteristics [21], and this was subsequently confirmed by nucleotide sequences analysis of the translation elongation factor 1- $\alpha(T E F-1 \alpha)$ genes with partial of representative strains. Of the forty-two strains, twenty-seven were identified as F. equiseti, ten as F. solani, and five as F. fujikuroi (Table 1). Previously, a new disease on pepper caused by F. concentricum was reported by our group, and the strain MUCL54697 was isolated from Hunan province, China [22].

Eleven representative strains belonging to different species were selected for TEF-1 $\alpha$ gene sequencing to further confirm the morphological identification results as described before [23-25]. Obtained sequences were subjected to alignment analysis using the network service tool BLASTn of the National Center for Biotechnology Information (NCBI) database. The sequence analysis of the portion of the TEF-1 $\alpha$ genes of representative strains confirmed that all the strains belonged to Fusarium genus. The results indicated that nucleotide sequences of three strains (Q12002, Q12003 and Q12005) showed the highest identity (>99\%) with the sequence of F. equiseti, three (Q12029, Q12030 and Q12034) showed the highest identity (>99\%) with the sequence of F. solani, and five (Q12038-Q12042) showed the highest identity (>99\%) with the sequence of F. fujikuroi in the NCBI database. The molecular identification results were all identical with the morphological results. The TEF-1 $\alpha$ gene sequences generated in this study were deposited in GenBank, NCBI (http://www.ncbi.nlm.nih.gov/genbank/), under accession numbers KF208617-KF208627, which is presented in Table 1. 
Table 1. Fusarium strains isolated in this study.

\begin{tabular}{|c|c|c|c|c|}
\hline Species & Strain Code & Origin & Symptom (External/Internal) & GenBank Accession No. \\
\hline \multirow[t]{27}{*}{ F. equiseti } & Q12001 & Shanghai & external & - \\
\hline & Q12002 & Shanghai & internal & KF208617 \\
\hline & Q12003 & Shanghai & external & KF208618 \\
\hline & Q12004 & Shanghai & external & - \\
\hline & Q12005 & Shanghai & internal & KF208619 \\
\hline & Q12006 & Shanghai & external & - \\
\hline & Q12007 & Shanghai & external & - \\
\hline & Q12008 & Shanghai & internal & - \\
\hline & Q12009 & Shanghai & external & - \\
\hline & Q12010 & Hainan & external & - \\
\hline & Q12011 & Shandong & external & - \\
\hline & Q12012 & Shandong & external & - \\
\hline & Q12013 & Shanghai & external & - \\
\hline & Q12014 & Shanghai & external & - \\
\hline & Q12015 & Shandong & external & - \\
\hline & Q12016 & Helongjiang & external & - \\
\hline & Q12017 & Zhejiang & external & - \\
\hline & Q12018 & Zhejiang & internal & - \\
\hline & Q12019 & Zhejiang & external & - \\
\hline & Q12020 & Zhejiang & external & - \\
\hline & Q12021 & Zhejiang & external & - \\
\hline & Q12022 & Zhejiang & internal & - \\
\hline & Q12023 & Zhejiang & external & - \\
\hline & Q12024 & Zhejiang & external & - \\
\hline & Q12025 & Hunan & external & - \\
\hline & Q12026 & Hunan & external & - \\
\hline & Q12027 & Hunan & external & - \\
\hline \multirow[t]{10}{*}{ F. solani } & Q12028 & Shanghai & external & - \\
\hline & Q12029 & Shanghai & external & KF208620 \\
\hline & Q12030 & Shanghai & external & KF208621 \\
\hline & Q12031 & Shanghai & external & - \\
\hline & Q12032 & Shanghai & external & - \\
\hline & Q12033 & Shanghai & external & - \\
\hline & Q12034 & Shanghai & internal & KF208622 \\
\hline & Q12035 & Shanghai & internal & - \\
\hline & Q12036 & Shanghai & external & - \\
\hline & Q12037 & Shanghai & external & - \\
\hline \multirow{5}{*}{ F. fujikuroi } & Q12038 & Hainan & external & KF208623 \\
\hline & Q12039 & Zhejiang & external & KF208624 \\
\hline & Q12040 & Zhejiang & external & KF208625 \\
\hline & Q12041 & Hunan & internal & KF208626 \\
\hline & Q12042 & Hunan & external & KF208627 \\
\hline
\end{tabular}

Among the forty-two Fusarium strains, all the ten F. solani (23.81\%) strains were isolated from Shanghai, and the five F. fujikuroi (11.90\%) strains were isolated from Hainan (one strain), Hunan (two strains), and Zhejiang (two strains). F. equiseti was the only species isolated from all six sampled provinces in China, and accounting for $64.29 \%$ of all Fusarium strains isolated (Table 1). According to our survey, F. equiseti was the predominant pathogen of sweet pepper fruit rot in China.

Fusarium strains were isolated from both external and internal rotten pepper fruits in this study. Of the forty-two strains, thirty-four were isolated from external rotten pepper fruits and eight strains were isolated from internal rotten pepper fruits (Table 1). For the twenty-seven F. equiseti strains, twenty-two were associated with external rot disease of pepper fruits and five (Q12002, Q12005, Q12008, Q12018, and Q12022) were isolated from internal rotten pepper fruits. For the ten F. solani and five F. fujikuroi, two (Q12034 and Q12035) and one strain (Q12041) were isolated from internal rotten pepper fruit, respectively. As such, F. equiseti, F. solani, and F. fujikuroi were the causal agents of external fruit rot of pepper in China, with F. equiseti being the predominant, while F. equiseti, F. solani, and F. fujikuroi were associated with internal fruit rot of pepper, with $F$. equiseti being the predominant. To our best knowledge, this is the first report of F. fujikuroi, F. equiseti, and F. solani associated with external and internal pepper fruit rot in China.

F. solani was reported as the predominant causal agent of external fruit rot of pepper in Europe and North America [7-13], which is different from China. However, it worth noting that F. solani is a common pathogen causing pepper fruit rot worldwide. F. solani, F. lactis, F. proliferatum, F. subglutinans, and F. verticillioides were reported to cause external or internal pepper fruit rot in Belgium, Canada, 
and United Kingdom, with F. lactis being the principal one [4,6,8]. In this study, F. equiseti, F. solani, and F. fujikuroi were found to be associated with internal pepper fruit rot, and with F. equiseti being the predominant. In light of the above, it is obvious that the population structure of Fusarium species associated with pepper fruit rot (external or internal) in China is quite different from those in surveys from Canada and Belgium $[4,8,10]$. Although the underlying factors for species distribution are unknown, climatic conditions (such as the annual temperature weather and humidity), hosts and their rotation, and adaptive evolution have been reported to influence the distribution of Fusarium species [14,26-28]. In view of the population genetic diversity and dispersal difference of the Fusarium pathogens, procedures for effective management of these pathogens on pepper are urgently needed.

\subsection{Molecular Phylogenetics}

Phylogenetic analyses were conducted on partial sequences of TEF- $1 \alpha$ genes. Figure 2 shows the phylogenetic tree constructed with MEGA 5.10 [29]. As several Fusarium species have been reported to be the causal agents of pepper fruit rot, in addition to the nucleotide sequences obtained in this study (Table 1), corresponding sequences available in GenBank for the strains belonging to F. concentricum, F. equiseti, F. fujikuroi, F. lactis, F. proliferatum, F. solani, F. subglutinans, and F. verticillioides were retrieved and served as references.

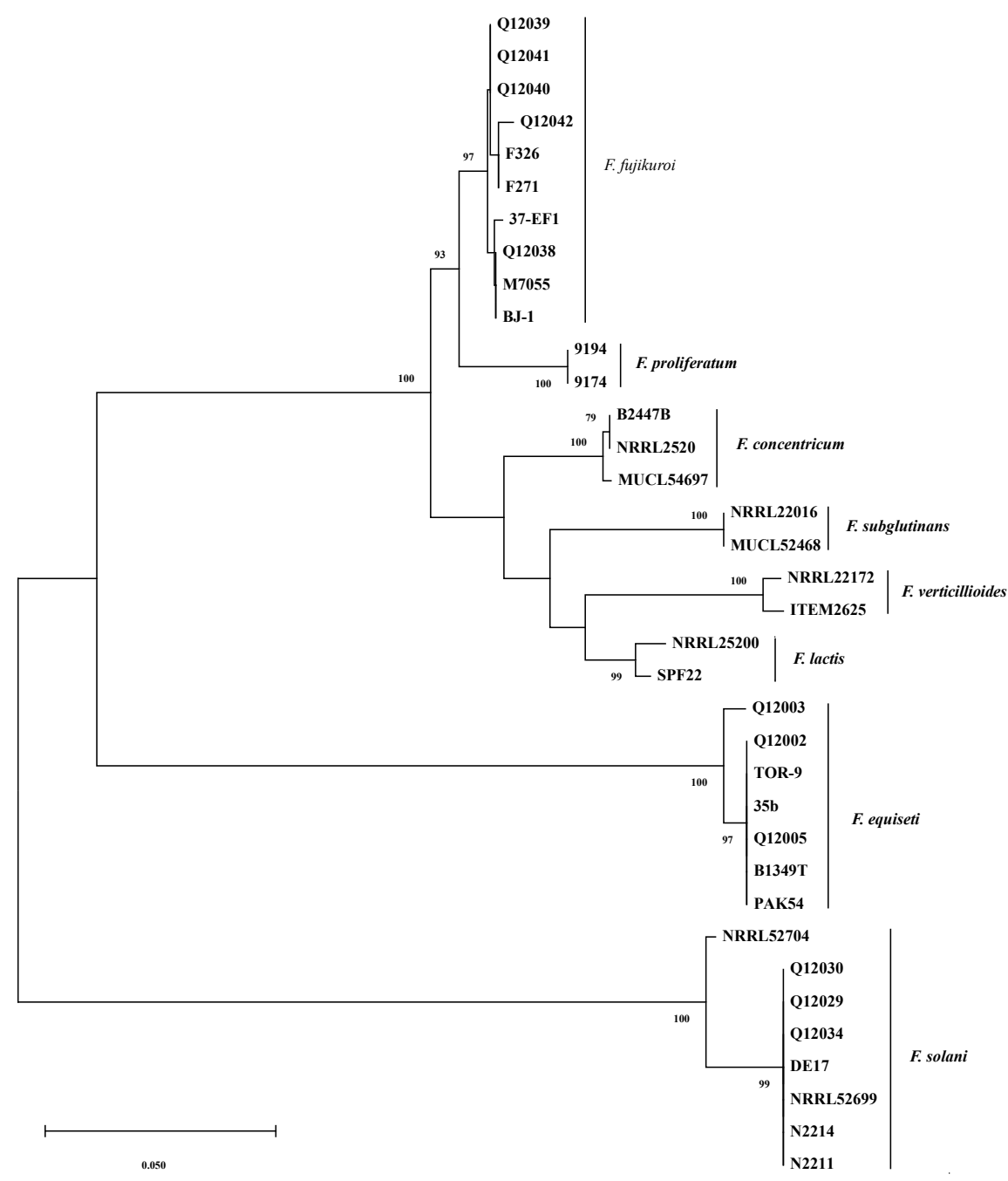

Figure 2. Phylogenetic tree inferred from alignments of TEF-1 $\alpha$ sequences of Fusarium species by the Neighbor-Joining method with program MEGA 5.10. The numbers beside branches are the percentages of congruent clusters in 1000 bootstrap trials. Bootstrap values higher than $75 \%$ are shown. 
As shown in Figure 2, bootstrap analyses of the TEF-1 $\alpha$ gene partial sequences clearly separated the thirty-six Fusarium isolates into three major clades with a bootstrap value of $100 \%$; the F. equiseti clade (seven isolates), the F. solani clade (eight isolates), and the third clade that was composed of the remaining twenty-one isolates belonging to F. concentricum, F. fujikuroi, F. lactis, F. proliferatum, F. subglutinans, and F. verticillioides. The six Fusarium species mentioned above in the third clade are all from the F. fujikuroi species complex (FFSC) [30], and they are relatively closer species among the species analyzed.

It is obvious that six distinct subclades were formed with $>97 \%$ bootstrap support in the third clade which separated the twenty-one isolates to F. concentricum (three isolates), F. fujikuroi (ten isolates), F. lactis (two isolates), F. proliferatum (two isolates), F. subglutinans (two isolates), and F. verticillioides (two isolates) (Figure 2). Thus, the TEF-1 $\alpha$ sequences can efficiently differentiate these Fusarium species. The TEF-1 $\alpha$ sequence BLASTn and phylogenetic analysis results strongly supported the identification results of Fusarium strains isolated.

\subsection{Multi-Mycotoxin Analysis in Pepper Fruit}

For large-scale screening of mycotoxin production capabilities in pepper by the sampled Fusarium isolates, the well-established multi-component LC-MS/MS method was used for scanning of the 36 mycotoxins reported in agricultural products. In this multi-mycotoxin analysis, two F. equiseti isolates (Q12002 and Q12004), three F. solani isolates (Q12029, Q12034 and Q12037), four F. fujikuroi isolates (Q12038, Q12039, Q12040 and Q12041), and the F. concentricum strain MUCL54697 [22] were selected to do the inoculation experiment and assess their mycotoxin production in different sites of sweet pepper fruits (Figure 3).

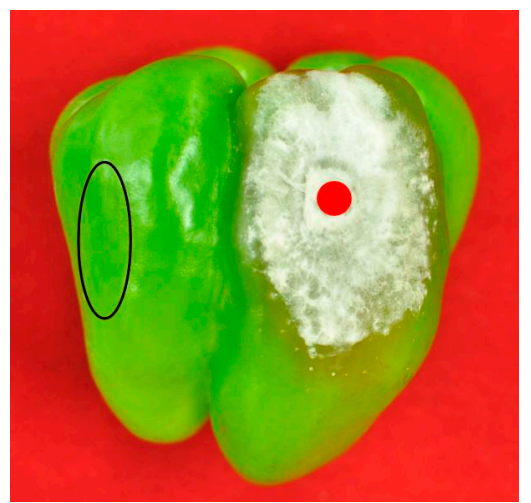

Figure 3. Inoculated pepper with the indication of inoculation site (red dot) and healthy site (black oval) for mycotoxin analysis.

Mycotoxin detection results from lesions (Figure 3, red dot) were used to do the mycotoxin profile analysis, and the results from the healthy parts (Figure 3, black oval) were used for the migration study. Mycotoxin profiles of the ten strains selected were summarized in Table 2. The multiple mycotoxin analysis resulted in the detection of $\mathrm{BEA}, \mathrm{FA}$, fumonisin $\mathrm{B}_{1}\left(\mathrm{FB}_{1}\right)$, fumonisin $\mathrm{B}_{2}\left(\mathrm{FB}_{2}\right), \mathrm{MON}$, and nivalenol (NIV) in pepper tissues (Figures 1 and 4). In one out of the ten isolates inoculated, none of the thirty-six mycotoxins investigated was detected. FA was the most frequently detected metabolite which was produced by nine isolates in concentrations that greatly varied from 41.44 to $10,662.36 \mu \mathrm{g} / \mathrm{kg}$. BEA was produced by eight isolates with average concentrations varying between 5.20 and $1019.60 \mu \mathrm{g} / \mathrm{kg}$. Both $\mathrm{FB}_{1}$ and $\mathrm{FB}_{2}$ were produced by the same four isolates ranging from 43.64 to $39,326.60 \mu \mathrm{g} / \mathrm{kg}$ and 26.96 to $3734.16 \mu \mathrm{g} / \mathrm{kg}$, respectively. MON was produced by five isolates in greatly varying amounts (35.80-2439.48 $\mu \mathrm{g} / \mathrm{kg})$, while NIV was produced by only one isolate at a concentration of $184.16 \mu \mathrm{g} / \mathrm{kg}$. 
Table 2. Mycotoxins produced by selected Fusarium strains in sweet pepper samples.

\begin{tabular}{|c|c|c|c|c|c|c|c|c|}
\hline \multirow{2}{*}{ Fusarium Species } & \multirow{2}{*}{$\begin{array}{l}\text { Strain } \\
\text { Code }\end{array}$} & \multirow{2}{*}{ Position $^{1}$} & \multicolumn{6}{|c|}{ Mycotoxins Detected $(\mu \mathrm{g} / \mathrm{kg})$} \\
\hline & & & BEA & FA & $\mathrm{FB}_{1}$ & $\mathrm{FB}_{2}$ & MON & NIV \\
\hline \multirow[t]{2}{*}{ F. equiseti } & Q12002 & IS & 5.20 & 411.64 & - & - & - & 184.16 \\
\hline & & HS & - & 13.80 & - & - & - & - \\
\hline \multirow{2}{*}{ F. equiseti } & Q12004 & IS & 9.12 & 160.32 & - & - & - & - \\
\hline & & HS & - & - & - & - & - & - \\
\hline \multirow[t]{2}{*}{ F. solani } & Q12029 & IS & - & 41.44 & - & - & - & - \\
\hline & & HS & - & - & - & - & - & - \\
\hline \multirow[t]{2}{*}{ F. solani } & Q12034 & IS & 98.48 & 78.98 & - & - & - & - \\
\hline & & HS & - & - & - & - & - & - \\
\hline \multirow{2}{*}{ F. solani } & Q12037 & IS & - & - & - & - & - & - \\
\hline & & HS & - & - & - & - & - & - \\
\hline \multirow[t]{2}{*}{ F. fujikuroi } & Q12038 & IS & 153.84 & 10662.36 & 1512.48 & 1190.12 & 2439.48 & - \\
\hline & & HS & - & 592.00 & 45.36 & 31.67 & 193.75 & - \\
\hline \multirow{2}{*}{ F. fujikuroi } & Q12039 & IS & 318.00 & 4870.56 & 1559.04 & 851.88 & 1429.76 & - \\
\hline & & HS & & 130.40 & 41.08 & 24.30 & 172.13 & - \\
\hline \multirow[t]{2}{*}{ F. fujikuroi } & Q12040 & IS & 44.44 & 6522.72 & 43.64 & 26.96 & 151.72 & - \\
\hline & & HS & - & 874.04 & - & - & - & - \\
\hline \multirow{2}{*}{ F. fujikuroi } & Q12041 & IS & 23.80 & 2940.72 & 3926.60 & 3734.16 & 1925.00 & - \\
\hline & & HS & - & 530.48 & 183.04 & 144.92 & 253.12 & - \\
\hline \multirow[t]{2}{*}{ F. concentricum } & MUCL54697 & IS & 1019.60 & 2886.08 & - & - & 35.80 & - \\
\hline & & HS & - & 55.64 & - & - & - & - \\
\hline
\end{tabular}

${ }^{1}$ IS, Inoculation site; HS, Healthy site.

(A)<smiles>O=c1cc(O[O-])c1=O</smiles>

(B)

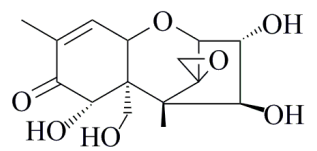<smiles>CC(C)C(Cc1ccccc1)C(=O)N(C)C(Cc1ccccc1)C(=O)OC(C(=O)N(C)C(Cc1ccccc1)C(=O)N(I)C(Cc1ccccc1)C(=O)NC(C(=O)O)C(=O)OC(C(C)C)C(C)C)C(C)C</smiles>

Figure 4. Structural formulas of moniliformin (A), nivalenol (B), fusariuc acid (C), and beauvericin (D).

As shown in Table 2, significantly different toxigenic profiles were observed among different species in inoculated pepper fruits. For the investigated Fusarium species, the most abundant of toxic metabolites were produced by F. fujikuroi, and all the four F. fujikuroi isolates can produce BEA, FA, $\mathrm{FB}_{1}, \mathrm{FB}_{2}$, and $\mathrm{MON}$. With regard to the individual mycotoxin, relatively higher contents of $\mathrm{FB}_{1}$ were generated compared to $\mathrm{FB}_{2}$ by the same strain, which were consistent with the previously reported studies [31,32]. The ratios between the two fumonisins for individual F. fujikuroi strain were in the range of 1.05-1.83 in pepper lesions. Meanwhile, significant differences in fumonisin production capacities of F. fujikuroi strains were observed. For example, strain Q12040 produced $\mathrm{FB}_{1}$ and $\mathrm{FB}_{2}$ in concentrations of $43.64,26.96 \mu \mathrm{g} / \mathrm{kg}$, respectively, while large amounts of $\mathrm{FB}_{1}$ and $\mathrm{FB}_{2}$ were produced by isolate Q12041 (3926.60, 3734.16 $\mu \mathrm{g} / \mathrm{kg}$, respectively) which were about 90 and 139 times as higher than those produced by Q12040 under the same conditions. Note that similar or higher amounts of FA and MON were produced by the four F. fujikuroi strains when compared with FBs. For example, the amount of FA is higher than the total fumonisins $\left(\mathrm{FB}_{1}+\mathrm{FB}_{2}\right)$ produced by three out of four isolates. Strain Q12002 produced NIV, a kind of type B trichothecene, at a concentration of $184.16 \mu \mathrm{g} / \mathrm{kg}$, while trichothecenes were not observed with the other strain Q12004. These two F. equiseti isolates showed a considerable intraspecies variation in profiles of trichothecene production, similar to results reported by Hestbjerg et al. [33]. Similarly, intraspecies variation in toxigenic profiles was also observed in 
F. solani. Regarding the three F. solani strains, only FA was produced by strain Q12029, compared to BEA and FA $(94.84,78.98 \mu \mathrm{g} / \mathrm{kg}$, respectively) that were produced by strain Q12034, while none of the thirty-six mycotoxins were detected with strain Q12037.

Large variation among strains, both in terms of their toxigenic profiles and the quantity of mycotoxins produced in pepper, was found in this study. Based on the mycotoxin profile results, it could be concluded that interspecies toxigenic profile variation appears to be a species-specific characteristic, while the intraspecies quantity variation appears to be a strain-specific characteristic.

The results of the migration study are summarized in Table 2. Among the mycotoxins detected in this study, diffusion phenomenon of $\mathrm{FA}, \mathrm{FB}_{1}, \mathrm{FB}_{2}$, and $\mathrm{MON}$ from a moldy area to healthy tissues was observed in pepper fruit, while no detectable BEA and NIV were found in unaffected parts.

As shown in Table 2, FA was the most frequently detected mycotoxin in unaffected parts, with concentrations varying from 13.80 to $874.04 \mu \mathrm{g} / \mathrm{kg}$. As a phytotoxin [34], the ratios of FA detected from lesions and healthy parts were in the range of 5.54-51.87. $\mathrm{FB}_{1}$ was detected in unaffected parts with concentrations varying from 41.08 to $183.04 \mu \mathrm{g} / \mathrm{kg}$. The ratios of $\mathrm{FB}_{1}$ detected from lesions and healthy parts were in the range of 21.45-37.95. $\mathrm{FB}_{2}$ was detected in unaffected parts with concentrations varying from 24.30 to $144.92 \mu \mathrm{g} / \mathrm{kg}$ and the ratios of $\mathrm{FB}_{2}$ detected from lesions and healthy parts were similar to $\mathrm{FB}_{1}$ (25.77-37.58). MON was detected in unaffected parts with concentrations varying from 172.13 to $253.12 \mu \mathrm{g} / \mathrm{kg}$, and the ratios of the compound from lesions and healthy parts were in the range of 7.61-12.59. Migration of $\mathrm{FB}_{1}$ and $\mathrm{FB}_{2}$ in sweet pepper was reported by Monbaliu et al. [19], and this is the first report about the diffusion of FA and MON in sweet pepper.

Mycotoxins can persist in infected plant tissues, and depending on physical or chemical properties (solubility, polarity, hydrophilicity, molecular weight, concentration, etc.) and tissue components, might also transfer from a rotten part of the plant tissues into the surrounding sound tissues, even in the absence of fungal growth. In this study, no NIV was detected in healthy pepper tissues maybe due to the low concentration, while BEA was not detected even at a high concentration $(1019.60 \mu \mathrm{g} / \mathrm{kg})$. Similar results were reported by Monbaliu et al. [19] that BEA can not be detected in surrounding tissues even with an extremely high concentration, $73,800 \mu \mathrm{g} / \mathrm{kg}$, in pepper lesions. As shown in Figure 4, BEA is a cyclic hexadepsipeptide that contains three D-hydroxyisovaleryl and three N-methylphenylalanyl residues in an alternating sequence [35]. As an organic and non-polar compound, BEA is insoluble in the aqueous environment. Vegetable, and sweet peppers in particular, contain $>90 \%$ water, which is probably why BEA was not detected in the surrounding tissues. These results demonstrated the possible risk of mycotoxin contamination in non-infected parts of food products, and some mycotoxins can diffuse into sound tissues. Since second-quality vegetables and fruits may be used to produce derivatives such as juices, jam, etc., further studies on migration behaviors and affecting factors of different mycotoxins in various vegetables and fruits are very important to establish suitable means of protecting consumers from exposure to toxic substances [20].

\section{Conclusions}

Fusarium species causing pepper fruit rot (external and internal) were analyzed in this study. Altogether, forty-two isolates belonging to F. equiseti (27 isolates), F. solani (10 isolates), and F. fujikuroi (five isolates) were identified with F. equiseti being the predominant species. To our best knowledge, this is the first report of F. fujikuroi, F. equiseti and F. solani associated with pepper fruit rot in China. Toxigenic profiles of ten pathogens were determined in sweet peppers, and six toxic metabolites (BEA, $\mathrm{FA}, \mathrm{FB}_{1}, \mathrm{FB}_{2}, \mathrm{MON}$, and NIV) were detected in total. Significantly different toxigenic profiles were observed among the three Fusarium species. Diffusions of $\mathrm{FA}, \mathrm{FB}_{1}, \mathrm{FB}_{2}$, and $\mathrm{MON}$ from lesions into the surrounding sound tissues were observed in sweet peppers, and this is the first report about the migration of FA and MON in sweet peppers. Further studies on migration behaviors and affecting factors of different mycotoxins in various vegetables and fruit should be conducted. 


\section{Materials and Methods}

\subsection{Isolation and Purification of Fusarium Strains}

During the growing season, pepper fruit samples were collected from different regions in China, including Hainan, Heilongjiang, Hunan, Shandong, Shanghai, and Zhejiang provinces (Table 1). Pepper fruits with visible symptoms (external or internal when cut open) were selected for pathogen isolation. Fungi were isolated using conventional methods as follows: Symptomatic tissues $(3 \times 3 \mathrm{~cm})$ were surface-sterilized in $0.1 \% \mathrm{HgCl}_{2}$ for $1 \mathrm{~min}$, transferred into $70 \%$ ethanol for $30 \mathrm{~s}$, then rinsed three times in sterilized distilled water, dried, and plated on $90 \mathrm{~mm}$ Petri dishes containing potato dextrose agar (PDA). After incubation for $3-5$ days at $28^{\circ} \mathrm{C}$ in the dark, colonies resembling morphologically to Fusarium were transferred onto new PDA. Plates were incubated at $28^{\circ} \mathrm{C}$ in the dark until colonies developed, and then purified through serial transfers. No more than one strain per fruit was isolated. For each strain, a single spore culture was obtained by single-sporing as described before [36]. The pure cultures were used for the morphological and molecular characterization. Monoconidial strains were cryopreserved and maintained in tubes on PDA in the lab.

\subsection{Nucleotide Maniplation}

Mycelia plugs from 3-day-old PDA cultures were transferred to $50 \mathrm{~mL}$ of potato dextrose broth (PDB) medium and incubated with shaking $(100 \mathrm{rpm})$ at $28^{\circ} \mathrm{C}$ in the dark for 3 days. After incubation, mycelium was filtered through two-layered cheesecloth, washed with sterile water, then freeze-dried and ground to a fine powder using a TissueLyser II system (Qiagen Tissuelyser II, Retsch, Haan, Germany). Genomic DNA was extracted and purified using a Cetyl Trimethylammonium Bromide (CTAB) protocol as described before [37]. In brief, after homogenization, the ground power was suspended with $600 \mu \mathrm{L}$ of CTAB lysis buffer, mixed well by shaking, and incubated at $65^{\circ} \mathrm{C}$ for $1 \mathrm{~h}$. After incubation, the solution was cooled at room temperature for $5 \mathrm{~min}$, cellular debris were pelleted by centrifugation at $12,000 \mathrm{rpm}$ for $10 \mathrm{~min}$, and $500 \mu \mathrm{L}$ of supernatant was transferred into a new tube. The supernatant was extracted with $500 \mu \mathrm{L}$ of chloroform:isoamyl alcohol mixture $(24: 1, v / v)$. After centrifugation at $12,000 \mathrm{rpm}$ for $10 \mathrm{~min}, 400 \mu \mathrm{L}$ of aqueous phase was transferred to a fresh tube, then $400 \mu \mathrm{L}$ of ice-cold isopropyl alcohol and $40 \mu \mathrm{L}$ of sodium acetate (3 M, pH 5.2) were subsequently added to the samples. The tubes were mixed by gentle inversion. After incubation for $1 \mathrm{~h}$ at $-20^{\circ} \mathrm{C}$, DNA was precipitated by centrifugation at $12,000 \mathrm{rpm}$ for $10 \mathrm{~min}$. The DNA sample was washed with $800 \mu \mathrm{L}$ of pre-chilled $70 \%$ ethanol and air-dried before resuspension in $50 \mu \mathrm{L}$ TE buffer $(10 \mathrm{mM}$ Tri-HCl, $0.1 \mathrm{mM}$ EDTA, $\mathrm{pH}$ 8.0). DNA quantification and quality analysis were carried out by agarose gel electrophoresis with known DNA marker as standard.

\subsection{Fusarium Strain Identification}

The purified Fusarium strains were identified to species by morphological characteristics, and this was confirmed by TEF-1 $\alpha$ gene sequence analysis of the representative strains. Methods for determining phenotypic characters and mycelial growth of Fusarium strains were from published protocols [21].

In order to verify the identity of Fusarium strains collected, DNA sequence comparisons were made for a subset of the strains using the TEF-1 $\alpha$ gene, known as one of the most pertinent gene for determining the species rank in the Fusarium genus [23-25]. Portions of the TEF-1 $\alpha$ gene were amplified with primer pair EF-1 ( $3^{\prime}$-ATGGGTAAGGA(A/G)GACAAGAC-5') and EF-2 ( $3^{\prime}$-GGA(G/A)GTACCAGT(G/C)ATCATGTT-5') in a thermal cycler. Polymerase chain reaction (PCR) was performed in a $50 \mu \mathrm{L}$ reaction system afterwards [4], with minor modifications. PCR reaction mixtures contained $1 \times$ TransStar FastPfu Fly PCR SuperMix (TransGen Biotech, Beijing, China), $0.2 \mu \mathrm{M}$ of each primer, and $50 \mathrm{ng}$ of genomic DNA template. A negative control omitting the DNA template was used in every set of reactions. The thermal cycler (T100 Thermal Cycler, Bio-Rad, Hercules, CA, USA) conditions consisted of an initial denaturation step at $94{ }^{\circ} \mathrm{C}$ for $2 \mathrm{~min}$, followed by 30 cycles of denaturation at $94{ }^{\circ} \mathrm{C}$ for $20 \mathrm{~s}$, annealing at $58{ }^{\circ} \mathrm{C}$ for $20 \mathrm{~s}$ and extension at $72{ }^{\circ} \mathrm{C}$ for $30 \mathrm{~s}$, then 
a final extension of $72{ }^{\circ} \mathrm{C}$ for $5 \mathrm{~min}$. Amplified products $(50 \mu \mathrm{L})$ were separated by electrophoresis on $1.5 \%(w / v)$ agarose gels. Gels were stained with ethidium bromide and photographed under UV light in the Bio-Imaging system (Bio-Rad, Hercules, CA USA). Fragments were excised and extracted from the gel using the QIAquick gel extraction kit (QIAGEN, Hilden, Germany) according to the manufacturer's instructions. Purified amplicons were sequenced in both directions using an ABI3730XL DNA sequencer (Applied Biosystems, Foster City, CA, USA) for each strain, and contigs were assembled with Sequencher version 4.1 program (Gene Codes Corporation). The TEF-1 $\alpha$ gene sequences generated in this study were subjected to similarity searches with the BLASTn network service of NCBI nucleotide database.

\subsection{Phylogenetic Analysis}

Portions of the TEF-1 $\alpha$ gene sequences from eleven Fusarium strains were generated for phylogenetic analysis in this study (Table 1). All sequences were compared with sequences of Fusarium species available in the GenBank database through BLASTn searches for similar sequences.

Phylogenetic analyses were conducted using MEGA v. 5.10 [29] to characterize the genetic diversity and evolutionary relationships of the strains. TEF-1 $\alpha$ sequences of twenty-five fungal strains belonging to Fusarium genus retrieved from the NCBI database were also used as references for constructing a phylogenetic tree. In total, thirty-six sequences were analyzed, including seven F. equiseti strains, ten F. fujikuroi strains, eight F. solani strains, three F. concentricum strains, two F. lactisi strains, two F. proliferatum strains, two F. subglutinans strains, and two F. verticillioides strains. The TEF-1 $\alpha$ sequences of these Fusarium strains were all available in NCBI nucleotide database, and detailed information about their strain code, geographic origin, and host/substrate is listed in Table 3.

Table 3. Fusarium strains used in phylogenetic analysis and their origins and GenBank accession numbers of TEF-1 $\alpha$ genes.

\begin{tabular}{|c|c|c|c|c|c|}
\hline Speices & Strain code & Origin & Host/Substrate & Accession number & Reference \\
\hline F. concentricum & B2447B & Malaysia & Banana & KY379181 & [38] \\
\hline F. concentricum & MUCL54697 & China & Sweet pepper & KC816735 & [22] \\
\hline F. concentricum & NRRL25202 & Korea & Delphacidae & JF740760 & [24] \\
\hline F. equiseti & $35 b$ & China & Wheat & KY466715 & - \\
\hline F. equiseti & B1349T & China & Tomato & KM886212 & - \\
\hline F. equiseti & PAK54 & USA & Loquat & KY523101 & - \\
\hline F. equiseti & Q12002 & China & Sweet pepper & KF208617 & This study \\
\hline F. equiseti & Q12003 & China & Sweet pepper & KF208618 & This study \\
\hline F. equiseti & Q12005 & China & Sweet pepper & KF208619 & This study \\
\hline F. equiseti & TOR-9 & Spain & Strawberry & KX215087 & [39] \\
\hline F. fujikuroi & 37-EF1 & Malaysia & Pineapple & KC584844 & - \\
\hline F. fujikuroi & BJ-1 & China & Bletilla striata & MH263736 & - \\
\hline F. fujikuroi & F271 & India & Rice & KM586385 & - \\
\hline F. fujikuroi & F326 & India & Rice & КР009955 & - \\
\hline F. fujikuroi & M7055 & China & Maize & КС964126 & [40] \\
\hline F. fujikuroi & Q12038 & China & Sweet pepper & KF208623 & This study \\
\hline F. fujikuroi & Q12039 & China & Sweet pepper & KF208624 & This study \\
\hline F. fujikuroi & Q12040 & China & Sweet pepper & KF208625 & This study \\
\hline F. fujikuroi & Q12041 & China & Sweet pepper & KF208626 & This study \\
\hline F. fujikuroi & Q12042 & China & Sweet pepper & KF208627 & This study \\
\hline F. lactisi & NRRL25200 & USA & Ficus carica & AF160272 & [41] \\
\hline F. lactisi & SPF22 & Korea & Sweet pepper & JF411959 & [5] \\
\hline F. proliferatum & 9174 & Malaysia & Pitaya & JX869021 & [42] \\
\hline F. proliferatum & 9194 & Malaysia & Pitaya & JX869025 & [42] \\
\hline F. solani & DE17 & Malaysia & Mangrove soil & KM096385 & - \\
\hline F. solani & N2211 & Malaysia & Cucurbits & KT211623 & - \\
\hline F. solani & N2214 & Malaysia & Cucurbits & KT211624 & - \\
\hline F. solani & NRRL52699 & Colombia & Cercopidae & JF740782 & [24] \\
\hline F. solani & NRRL52704 & USA & Tetranychidae & JF740786 & [24] \\
\hline F. solani & Q12029 & China & Sweet pepper & KF208620 & This study \\
\hline F. solani & Q12030 & China & Sweet pepper & KF208621 & This study \\
\hline F. solani & Q12034 & China & Sweet pepper & KF208622 & This study \\
\hline F. subglutinans & MUCL52468 & Belgium & Maize & HМ067691 & [25] \\
\hline F. subglutinans & NRRL22016 & USA & Maize & AF160289 & {$[25,41,43]$} \\
\hline F. verticillioides & ITEM2625 & Slovakia & Maize & KF715264 & - \\
\hline F. verticillioides & NRRL22172 & Germany & Maize & AF160262 & {$[25,41,43]$} \\
\hline
\end{tabular}


All sequences were aligned initially with ClustalX software [44] and the alignments manually edited. Phylogenetic analyses of the sequences were performed with MEGA5.1 for Neighbor-joining (NJ) analysis, and Kimura-2 parameter model and pairwise deletion option for gaps were used. The reliability of the tree topologies was evaluated using bootstrap support with 1000 pseudoreplicates of the data.

\subsection{Mycotoxin Production Analysis in Pepper Fruits via LC-MS/MS}

Fungal strains were initially grown on PDA in $90 \mathrm{~mm}$ diameter Petri dishes for 7 days at $28^{\circ} \mathrm{C}$ in the dark, after which they were used to inoculate pepper fruits. Mature pepper fruits were inoculated with mycelium plug as described by Van Poucke et al. [4]. After incubation, the fruit tissues from different positions, including the inoculation site and healthy site, were collected, homogenized separately, and processed for mycotoxin detection analysis. Mycotoxin detection results from lesions were used to do the mycotoxin profile analysis, and the results from the healthy parts were used for the migration study.

For each sample, $2 \mathrm{~g}$ of the grounded material was extracted with $8 \mathrm{~mL}$ extraction solvent (acetonitrile:water $=84: 16, v / v$ ). Multi-component analysis of mycotoxins in the inoculated samples was performed as described previously $[45,46]$. In total, 36 mycotoxins were included in the multi-mycotoxin analyses: Aflatoxin $B_{1}\left(\mathrm{AFB}_{1}\right)$, aflatoxin $\mathrm{B}_{2}\left(\mathrm{AFB}_{2}\right)$, aflatoxin $\mathrm{G}_{1}\left(\mathrm{AFG}_{1}\right)$, aflatoxin $\mathrm{G}_{2}\left(\mathrm{AFG}_{2}\right)$, aflatoxin $\mathrm{M}_{2}\left(\mathrm{AFM}_{2}\right)$, aflatoxin $\mathrm{M}_{1}\left(\mathrm{AFM}_{1}\right)$, beauvericin (BEA), citrinin (CIT), cyclopiazonic acid (CPA), deoxynivalenol (DON), 3-acetyldeoxynivalenol (3-ADON), 15-acetyldeoxynivalenol (15-ADON), deoxynivalenol-3-glucoside (DON-3G), deepoxydeoxynivalenol (Deep-DON), diacetoxyscirpenol (DAS), fusaric acid (FA), fumonisin $\mathrm{B}_{1}\left(\mathrm{FB}_{1}\right)$, fumonisin $\mathrm{B}_{2}\left(\mathrm{FB}_{2}\right)$, fusarenon-X (FUSX), gliotoxin, HT2 toxin (HT2), moniliformin (MON), neosolaniol (NEO), nivalenol (NIV), ochratoxin A (OTA), patulin (PAT), penitrem A (PenA), sterigmatocystin (SMC), T-2 toxin (T-2), verruculogen (VER), zearalenone (ZEN), $\alpha$-zearalanol $(\alpha$-ZOL), $\beta$-zearalanol ( $\beta$-ZOL), $\alpha$-zearalenol $(\alpha$-ZAL), $\beta$-zearalenol $(\beta$-ZAL), and zearalanone (ZAN). HPLC or analytical grade of acetonitrile, hexane, and other chemical agents were purchased from Merck (Darmstadt, Germany). Deionized water purified by a Milli-Q water system (Millipore, Billerica, MA, USA) was used throughout the experiments.

Author Contributions: S.W. and J.W. collected the samples; Z.Z. performed the mycotoxin analysis; S.W., S.L. and J.W. performed the experiments and analyzed the data; F.V.H. provided some protocols for isolation; writing_original draft preparation, J.W.; writing—review and editing, A.W.; supervision, A.W.

Funding: This research was funded by the National Key Research and Development Program of China (2017YFC1600304), National Natural Science Foundation of China (31871896, 31401598, and 31602124), Shanghai Agriculture Commission Basic Research Programs (2014NO.7-3-7 and 2011NO.4-3).

Conflicts of Interest: The authors declare no conflict of interest.

\section{References}

1. Vanderslice, J.T.; Higgs, D.J.; Hayes, J.M.; Block, G. Ascorbic acid and dehydroascorbic acid content of foods-as-eaten. J. Food Compos. Anal. 1990, 3, 105-118. [CrossRef]

2. Speranza, G.; Lo Scalzo, R.; Morelli, C.F.; Rabuffetti, M.; Bianchi, G. Influence of drying techniques and growing location on the chemical composition of sweet pepper (Capsicum annuum L., var. Senise). J. Food Biochem. 2019, e13031. [CrossRef] [PubMed]

3. Qin, C.; Yu, C.S.; Shen, Y.; Fang, X.D.; Chen, L.; Min, J.M.; Cheng, J.; Zhao, S.; Xu, M.; Luo, Y.; et al. Whole-genome sequencing of cultivated and wild peppers provides insights into Capsicum domestication and specialization. Proc. Natl. Acad. Sci. USA 2014, 111, 5135-5140. [CrossRef] [PubMed]

4. Van Poucke, K.; Monbaliu, S.; Munaut, F.; Heungens, K.; De Saeger, S.; Van Hove, F. Genetic diversity and mycotoxin production of Fusarium lactis species complex isolates from sweet pepper. Int. J. Food Microbiol. 2012, 153, 28-37. [CrossRef] [PubMed]

5. Choi, H.W.; Hong, S.K.; Kim, W.G.; Lee, Y.K. First report of internal fruit rot of sweet pepper in Korea caused by Fusarium lactis. Plant Dis. 2011, 95, 1476. [CrossRef] [PubMed] 
6. Yang, Y.; Bouras, N.; Yang, J.; Howard, R.J.; Strelkov, S.E. Mycotoxin production by isolates of Fusarium lactis from greenhouse sweet pepper (Capsicum annuum). Int. J. Food Microbiol. 2011, 151, 150-156. [CrossRef] [PubMed]

7. Fletcher, J.T. Fusarium stem and fruit rot of sweet peppers in the glasshouse. Plant Pathol. 1994, 43, $225-227$. [CrossRef]

8. Yang, J.; Kharbanda, P.D.; Howard, R.J.; Mirza, M. Identification and pathogenicity of Fusarium lactis, causal agent of internal fruit rot of greenhouse sweet pepper in Alberta. Can. J. Plant Pathol. 2009, 31, 47-56. [CrossRef]

9. Howard, R.J.; Garland, J.A.; Seaman, W.L. Disease and Pests of Vegetable Crops in Canada, 1st ed.; The Canadian Phytopathological Society and Entomological Society of Canada: Ottawa, ON, Canada, 1994; pp. 333-336.

10. Yang, Y.; Cao, T.; Yang, J.; Howard, R.J.; Kharbanda, P.D.; Strelkov, S.E. Histopathology of internal fruit rot of sweet pepper caused by Fusarium lactis. Can. J. Plant Pathol. 2010, 32, 86-97. [CrossRef]

11. Utkhede, R.; Mathur, S. Fusarium fruit rot of greenhouse sweet peppers in Canada. Plant Dis. 2003, 87, 100. [CrossRef]

12. Utkhede, R.; Mathur, S. Internal fruit rot caused by Fusarium subglutinans in greenhouse sweet peppers. Can. J. Plant Pathol. 2004, 26, 386-390. [CrossRef]

13. Jarvis, W.R.; Khosla, S.K.; Barrie, S.D. Fusarium stem and fruit rot of sweet pepper in Ontario greenhouses. Can. Plant Dis. Surv. 1994, 74, 131-134.

14. Frans, M.; Aerts, R.; Van Laethem, S.; Ceusters, J. Environmental effects on growth and sporulation of Fusarium spp. causing internal fruit rot in bell pepper. Eur. J. Plant Pathol. 2017, 149, 875-883. [CrossRef]

15. Kharbanda, P.D.; Yang, J.; Howard, R.J.; Mirza, M. Internal fruit rot of greenhouse peppers caused by Fusarium lactis-a new disease. Greenh. Bus. 2006, 5, 11-16.

16. Chu, F.S.; Liu, G.Y. Simultaneous occurrence of fumonisin $B_{1}$ and other mycotoxins in moldy corn collected from People's Republic of China in regions with high incidences of esophageal cancer. Appl. Environ. Microb. 1994, 60, 847-852.

17. Peraica, M.; Radic, B.; Lucic, A.; Pavlovic, M. Toxic effects of mycotoxins in humans. Bull. World Health Organ. 1999, 77, 754-766. [PubMed]

18. Yazar, S.; Omurtag, G.Z. Fumonisins, trichothecenes and zearalenone in cereals. Int. J. Mol. Sci. 2008, 9, 2062-2090. [CrossRef] [PubMed]

19. Monbaliu, S.; Van Poucke, K.; Heungens, K.; Van Peteghem, C.; De Saeger, S. Production and migration of mycotoxins in sweet pepper analyzed by multimycotoxin LC-MS/MS. J. Agric. Food Chem. 2010, 58, 10475-10479. [CrossRef]

20. Restani, P. Diffusion of mycotoxins in fruits and vegetables. In Mycotoxins in Fruits and Vegetables, 1st ed.; Barkai-Golan, R., Paster, N., Eds.; Academic Press: San Diego, CA, USA, 2008; pp. 105-114.

21. Leslie, J.F.; Summerell, B.A. The Fusarium Lab Manual, 1st ed.; Blackwell Publishing: Ames, IA, USA, 2006; pp. 3-274.

22. Wang, J.H.; Feng, Z.H.; Han, Z.; Song, S.Q.; Lin, S.H.; Wu, A.B. First report of pepper fruit rot caused by Fusarium concentricum in China. Plant Dis. 2013, 97, 1657. [CrossRef]

23. O’Donnell, K.; Kistler, H.C.; Cigelnik, E.; Ploetz, R.C. Multiple evolutionary origins of the fungus causing Panama disease of banana: Concordant evidence from unclear and mitochondrial gene genealogies. Proc. Natl. Acad. Sci. USA 1998, 95, 2044-2049. [CrossRef]

24. O’Donnell, K.; Humber, R.A.; Geiser, D.M.; Kang, S.; Park, B.; Robert, V.A.; Crous, P.W.; Johnston, P.R.; Aoki, T.; Rooney, A.P.; et al. Phylogenetic diversity of insecticolous fusaria inferred from multilocus DNA sequence data and their molecular identification via FUSARIUM-ID and Fusarium MLST. Mycologia 2012, 104, 427-445. [CrossRef] [PubMed]

25. Scauflaire, J.; Gourgue, M.; Munaut, F. Fusarium temperatum sp. nov. from maize, an emergent species closely related to Fusarium subglutinans. Mycologia 2011, 103, 586-597. [CrossRef] [PubMed]

26. Ward, T.J.; Bielawski, J.P.; Kistler, H.C.; Sullivan, E.; O’Donnell, K. Ancestral polymorphism and adaptive evolution in the trichothecene mycotoxin gene cluster of phytopathogenic Fusarium. Proc. Natl. Acad. Sci. USA 2002, 9, 9278-9283. [CrossRef] [PubMed]

27. Jennings, P.; Coates, M.E.; Turner, J.A.; Chandler, E.A.; Nicholson, P. Determination of deoxynivalenol and nivalenol chemotypes of Fusarium culmorum isolates from England and Wales by PCR assay. Plant Pathol. 2004, 53, 182-190. [CrossRef]

28. Yang, L.; van der Lee, T.; Yang, X.; Yu, D.; Waalwijk, C. Fusarium populations on Chinese barley show a dramatic gradient in mycotoxin profiles. Phytopathology 2008, 98, 719-727. [CrossRef] [PubMed] 
29. Tamura, K.; Peterson, D.; Peterson, N.; Stecher, G.; Nei, M.; Kumar, S. MEGA5: Molecular evolutionary genetics analysis using maximum likelihood, evolutionary distance, and maximum parsimony methods. Mol. Biol. Evol. 2011, 28, 2731-2739. [CrossRef]

30. Al-Hatmi, A.M.S.; Mirabolfathy, M.; Hagen, F.; Normand, A.; Stielow, J.B.; Karami-Osbo, R.; Van Diepeningen, A.D.; Meis, J.F.; De Hoog, G.S. DNA barcoding, MALDI-TOF, and AFLP data support Fusarium ficicrescens as a distinct species within the Fusarium fujikuroi species complex. Fungal Biol. 2016, 120, 265-278. [CrossRef]

31. Wulff, E.G.; Sorense, J.L.; Lubeck, M.; Nielsen, K.F.; Thrane, U.; Torp, J. Fusarium spp. associated with rice bakanae: Ecology, genetic diversity, pathogenicity and toxigenicity. Environ. Microbiol. 2010, 12, 649-657. [CrossRef]

32. Stepien, L.; Koczyk, G.; Waskiewicz, A. FUM cluster divergence in fumonisins-producing Fusarium species. Fungal Biol. 2011, 115, 112-123. [CrossRef]

33. Hestbjerg, H.; Nielsen, K.F.; Thrane, U.; Elmholt, S. Production of trichothecenes and other secondary metabolites by Fusarium culmorum and Fusarium equiseti on common laboratory media and a soil organic matter agar: An ecological interpretation. J. Agric. Food Chem. 2002, 50, 7593-7599. [CrossRef]

34. Stankovic, S.; Levic, J.; Petrovic, T.; Logrieco, A.; Moretti, A. Pathogenicity and mycotoxin production by Fusarium proliferatum isolated from onion and garlic in Serbia. Eur. J. Plant Pathol. 2007, 118, 165-172. [CrossRef]

35. Wang, Q.G.; Xu, L.J. Beauvericin, a bioactive compound produced by fungi: A short review. Molecules 2012, 17, 2367-2377. [CrossRef] [PubMed]

36. Qu, B.; Li, H.P.; Zhang, J.B.; Xu, Y.B.; Huang, T.; Wu, A.B.; Zhao, C.S.; Carter, J.; Nicholson, P.; Liao, Y.C. Geographic distribution and genetic diversity of Fusarium graminearum and F. asiaticum on wheat spikes throughout China. Plant Pathol. 2008, 57, 15-24. [CrossRef]

37. Wang, J.H.; Li, H.P.; Qu, B.; Zhang, J.B.; Huang, T.; Chen, F.F.; Liao, Y.C. Development of a generic PCR detection of 3-acetyldeoxynivalenol, 15-acetyldeoxynivalenol- and nivalenol-chemotypes of Fusarium graminearum clade. Int. J. Mol. Sci. 2008, 9, 2495-2504. [CrossRef]

38. Abd Murad, N.B.; Mohamed Nor, N.N.; Shohaimi, S.; Mohd Zainudin, N.A.I. Genetic diversity and pathogenicity of Fusarium species associated with fruit rot disease in banana across Peninsular Malaysia. J. Appl. Microbiol. 2017, 123, 1533-1546. [CrossRef]

39. Pastrana, A.M.; Basallote-Ureba, M.J.; Aquado, A.; Capote, N. Potential inoculum sources and incidence of strawberry soilborne pathogens in Spain. Plant Dis. 2017, 101, 751-760. [CrossRef]

40. Wang, J.H.; Zhang, J.B.; Li, H.P.; Gong, A.D.; Xue, S.; Agboola, R.S.; Liao, Y.C. Molecular identification, mycotoxin production and comparative pathogenictiy of Fusarium temperatum isolated from maize in China. J. Phytopathol. 2013. [CrossRef]

41. Lima, C.S.; Pfenning, L.H.; Costa, S.S.; Abreu, L.M.; Leslie, J.F. Fusarium tupiense sp. nov., a member of the Gibberella fujikuroi complex that causes mango malformation in Brazil. Mycologia 2012, 104, 1408-1419. [CrossRef]

42. Masratul Hawa, M.; Salleh, B.; Latiffah, Z. Characterization and pathogenicity of Fusarium proliferatum causing stem rot of Hylocereus polyrhizus in Malaysia. Ann. Appl. Biol. 2013, 163, 269-280. [CrossRef]

43. Skovgaard, K.; Rosendahl, S.; O'Donnell, K.; Nirenberg, H.I. Fusarium commune is a new species identified by morphological and molecular phylogenetic data. Mycologia 2003, 95, 630-636. [CrossRef]

44. Thompson, J.D.; Gibson, T.J.; Plewniak, F.; Jeanmougin, F.; Higgins, D.G. The Clustal X windows interface: Flexible strategies for multiple sequence alignment aided by quality analysis tools. Nucleic Acids Res. 1997, 25, 4876-4882. [CrossRef]

45. Monbaliu, S.; Van Poucke, C.; Van Peteghem, C.; Van Poucke, K.; Heungens, K.; De Saeger, S. Development of a multi-mycotoxin liquid chromatography/tandem mass spectrometry method for sweet pepper analysis. Rapid Commun. Mass Spectrom. 2009, 23, 3-11. [CrossRef]

46. Zhao, Z.Y.; Yang, X.L.; Zhao, X.Y.; Chen, L.; Bai, B.; Zhou, C.Y.; Wang, J.H. Method development and validation for the analysis of emerging and traditional fusarium mycotoxins in pepper, potato, tomato, and cucumber by UPLC-MS/MS. Food Anal. Methods 2018, 11, 1780-1788. [CrossRef]

(C) 2019 by the authors. Licensee MDPI, Basel, Switzerland. This article is an open access article distributed under the terms and conditions of the Creative Commons Attribution (CC BY) license (http://creativecommons.org/licenses/by/4.0/). 